\title{
EXTRACTION OF ELEMENT AT RISK FOR LANDSLIDES USING REMOTE SENSING METHOD
}

\author{
Rozaimi Che Hasan ${ }^{1}$, Qalam A'zad Rosle ${ }^{2}$, Mohd Asraff Asmadi ${ }^{3}$ and Nur Afiqah Mohd Kamal ${ }^{4}$ \\ ${ }^{1}$ Razak Faculty of Technology and Informatics, Universiti Teknologi Malaysia Kuala Lumpur - rozaimi.kl@utm.my \\ ${ }^{2}$ Minerals and Geoscience Department (Selangor/Wilayah Persekutuan) Malaysia - qalam@jmg.gov.my \\ ${ }^{3}$ Faculty of Built Environment and Geoinformation, Universiti Teknologi Malaysia, Johor - asraff65@ gmail.com \\ ${ }^{4}$ Malaysian-Japan International Institute of Technology, Universiti Teknologi Malaysia, Kuala Lumpur - \\ afiqahhkamal@gmail.com
}

KEY WORDS: Landslides, hazard, risk, element at risk, LiDAR, remote sensing,

\begin{abstract}
:
One of the most critical steps towards landslide risk analysis is the determination of element at risk. Element at risk describes any object that could potentially fail or exposed to hazards during disaster. Without quantification of element at risk information, it is difficult to estimate risk. This paper aims at developing a methodology to extract and quantity element at risk from airborne Light Detection and Ranging (LiDAR) data. The element at risk map produced was then used to construct exposure map which describes the amount of hazard for each element at risk involved. This study presented two study sites at Kundasang and Kota Kinabalu in Sabah with both areas have experienced major earthquake in June 2015. The results show that not all the features can be automatically extracted from the LiDAR data. For example, automatic extraction process could be done for building footprint and building heights, but for others such as roads and vegetation areas, a manual digitization is still needed because of the difficulties to differentiate between these features. In addition to this, there were also difficulties in identifying attribute for each feature, for example to separate between federal roads with state and unpaved roads. Therefore, for large area hazard and risk mapping, the authors suggested that an automatic process should be investigated in the future to reduce time and cost to extract important features from LiDAR data.
\end{abstract}

\section{INTRODUCTION}

Slope failures, landslides or any form of mass movements pose serious hazards yet are difficult to predict (McColl, 2015, Brideau and Roberts, 2015, Couture and Evans, 2006). Despite remarkable efforts of mapping, monitoring and modelling of such major events at regional or local scales, quantifying the processes and activities of the hillslope and tectonic geomorphology is very challenging. Combined with anthropogenic activities, especially the development and settlement on unstable tropical terrain, landslides as natural processes in the first place have become natural disasters. Given that landslides often cause extensive damage to infrastructure and many casualties, it is important to identify the extent of slope failures, to define their characteristics and to estimate their activity (McKean and Roering, 2004).

Disaster risk is a function of hazard, exposure and vulnerability, expressed as the probability of loss of life, injury, and destroyed or damaged capital stock in a given period (De Bono and Mora, 2014). A comprehensive risk assessment and analysis is required for a better risk management. It must be evaluated with reference to a return period. Maps showing the areas that may be affected by landslides are a common tool used by authorities and decision makers to interact with the public and local community.

In any disaster, there will be objects that could potentially fail or be exposed to hazards. These are called elements at risk. The extraction and generation of the elements at risk for landslides is part of the activities in landslide risk assessment. The quality of elements at risk mapping can be improved with the use of high density LIDAR data (Du et al., 2017, Kumar et al., 2013). Some common examples are population, buildings and engineering structures, economic activities, public services, utilities, and cultural and environmental features in the area potentially affected by landslides (Razak et al., 2011, van Westen et al., 2008). As a result of elements at risk mapping, the level of hazard and risk can be properly defined. Moreover, the magnitude of a hazard or risk, expressed in terms of probability or likelihood for hazard and consequence for risk can be subsequently analyzed. This paper will address the methodology the authors developed to characterizing elements at risk from LiDAR data and how this information can be useful for landslide risk assessment.

\section{METHODS}

The study site is located at Kundasang and Kota Kinabalu (both in Sabah, Malaysia). These two sites were chosen as these areas have experienced earthquake and aftershocks. The major earthquake struck Sabah (especially Kundasang area) in June 2015 with 6.1 magnitude and hit some parts of Mount Kinabalu, which is one of the main tourist areas in Sabah. With unstable hilly slopes and considerable number of landslides (Sharir et al., 2016, Omar et al., 2016), Kundasang was considered suitable for the study. Kota Kinabalu was also included in this study as it is an urban area with high density population and could be affected by earthquake in Kundasang.

The main dataset used in study was collected using airborne LiDAR, acquired on August 2015 using RIEGL airborne LiDAR system. The final output from this system consists of 3D point clouds (in LAS format), $0.25 \mathrm{~m}$ Digital Terrain Model (DTM), 0.25m Digital Surface Model (DSM) and $0.07 \mathrm{~m}$ orthophoto. One of the essential information that 
was required in producing element at risk analysis was building footprint from the LiDAR data. This was completed using Global Mapper software v16 and ArcGIS v10.1. First, the building footprint was extracted from the 3D point cloud in Global Mapper. Secondly, the results were exported to ArcGIS to perform smoothing and filtering of building footprint polygons using aggregation process (aggregation distance of 1 meter). The specified aggregation distance was chosen based on several trial and error process as well as to maintain the shape of the buildings. In this stage, the selected distance will cluster adjacent points for building footprint to create a smooth building polygon. The attribute categories for building class are commercial, residential, industrial, public facility and institution. For road layer, extraction was using manual digitization process, with the same aerial orthophoto and hill shaded DTM layer to provide the operators with another angle of view and ease the digitizing process. The categories for road attribute are federal, state, rural and unpaved roads.

Building height is one of the valuable information that can be obtained from the airborne LiDAR dataset. This height can be obtained automatically for each of the building footprints with good accuracy. This information was obtained from Normalized Digital Surface Model (nDSM) where each pixel in the raster image contained values representing height of features. The process of extracting the height values was done using zonal statistics function (i.e. ArcGIS software) where the values from pixels were selected within the building footprint and merged with the attribute table of building polygon. After each of the building polygons were assigned individual height, it was then randomly validated using Google Street View to maintain consistency and data accuracy. This method was applied to both Kota Kinabalu and Kundasang areas.

The analysis of element at risk was carried out by looking at the potential areas where the elements are located near to the natural landslides and man-made slope failure. The analysis took 100 meters of buffering distance from the landslide and man-made slope polygons and any features of element at risk that lies within the zones were extracted. This process will identify the potential candidates that should be included in next analysis. Initially, 50 meters of distance was tested as the buffering distance. As a result, the buffering zone was to small and only few buildings were included in the analysis for both areas. This produced irrelevant results and most likely these features will not be affected by any hazard. In contrast, another test that was done using 200 meters buffering distance and showed that there were too many buildings affected, although these building were located very far from the center of the polygons. Therefore, 100 meters buffering distance was deemed as appropriate distance for these areas after considering these factors. Note that other areas with different settings might need different values. In addition to this, the information from the element at risk analysis was used to produce exposure map. Exposure indicates the degree to which the elements at risks are in an area affected by a hazard. The spatial interaction between the elements at risks and the hazard footprints were depicted in a GIS by map overlaying of the hazard map with the element at risks map.

\section{RESULTS AND DISCUSSION}

The affected buildings and roads within the buffering zones can be explained in statistics form as in Tables 1-4 while Figures 1-2 illustrates how the analysis were done and present some of the outputs from the process. The results for element at risk map of buildings and roads for Kota Kinabalu and Kundasang are shown in Figures 3-4.

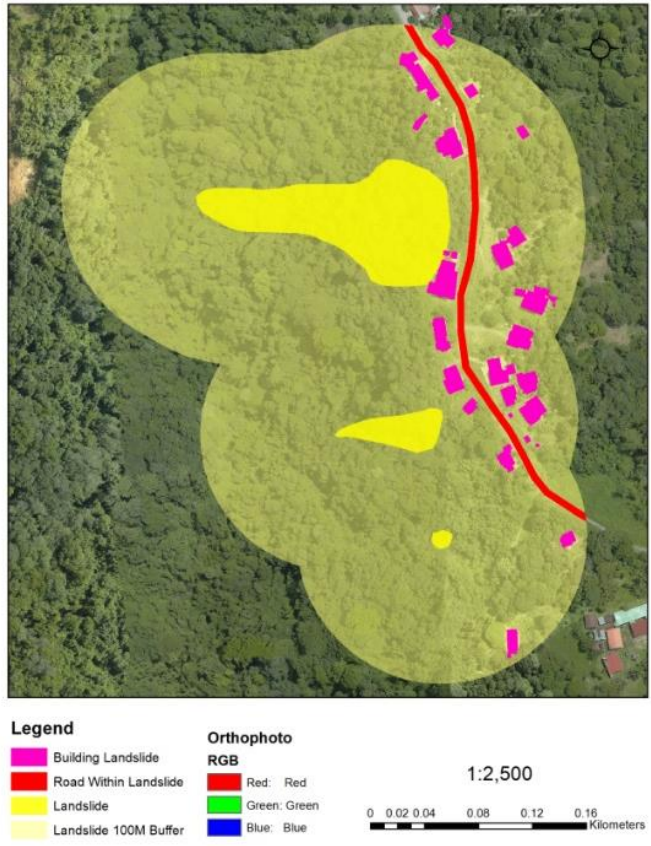

Figure 1: Illustration of how potential candidates are chosen for element at risk analysis using 100 meters buffering zone from landslide polygon.

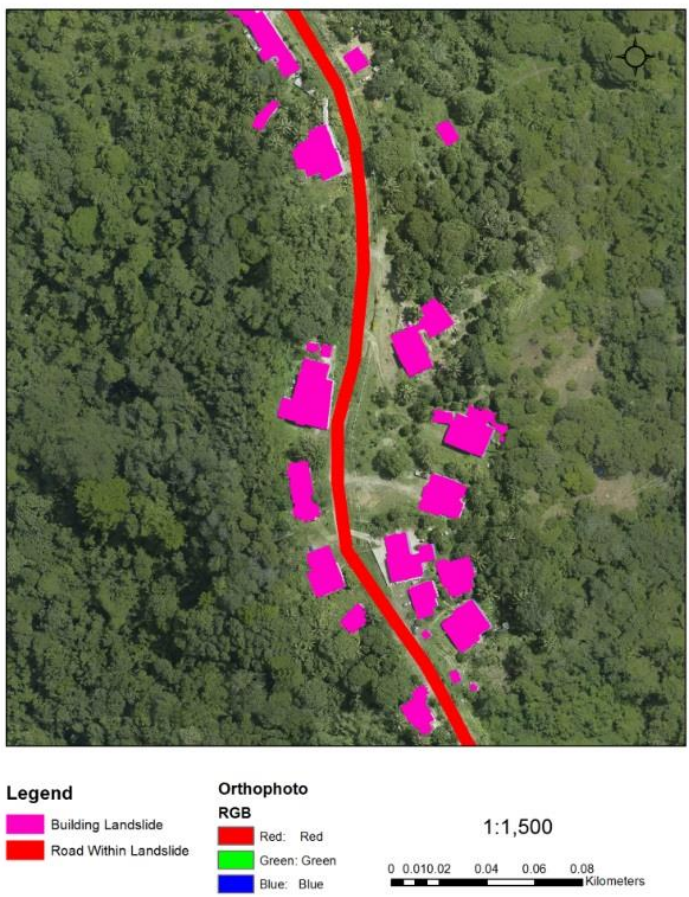

Figure 2: Example of element at risk (building and road) 
The International Archives of the Photogrammetry, Remote Sensing and Spatial Information Sciences, Volume XLII-4/W9, 2018 International Conference on Geomatics and Geospatial Technology (GGT 2018), 3-5 September 2018, Kuala Lumpur, Malaysia

The results show that about 6,146 out of 28,823 total buildings in Kota Kinabalu which is $21.32 \%$ of buildings are at risk (Table 1). As for roads in Kota Kinabalu as shown in the table, about half from total length of roads which are $53.15 \%$ are at risk. About 345.71 kilometers out of 650.49 kilometers of roads are contained within the buffer zone. These buildings and roads which are located 100 meters away from the location of landslides and slope failure are considered as element at risk and needs some precautions to prevent any casualties.

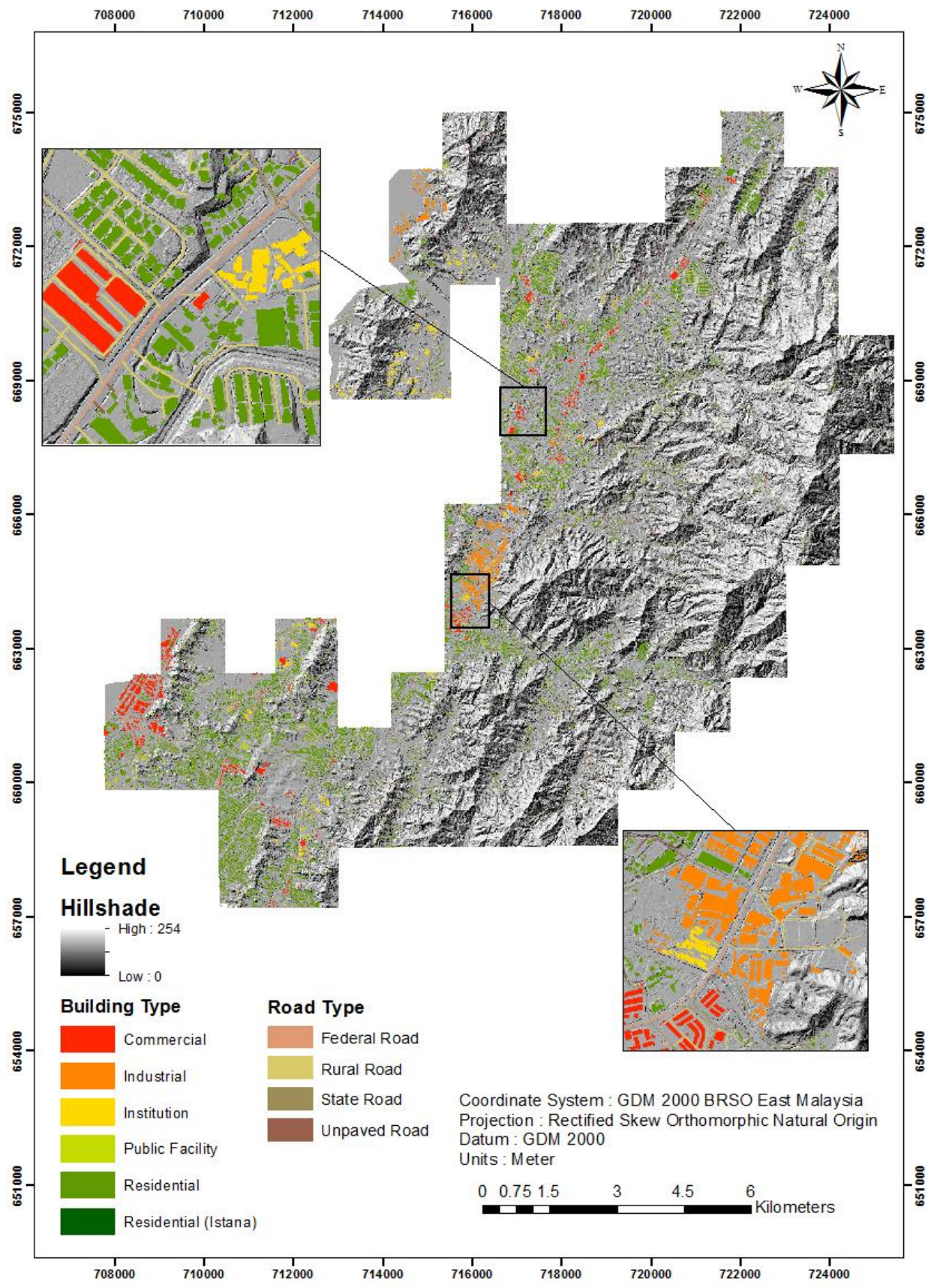

Figure 3:Landslide element at risk map of Kota Kinabalu 
The International Archives of the Photogrammetry, Remote Sensing and Spatial Information Sciences, Volume XLII-4/W9, 2018 International Conference on Geomatics and Geospatial Technology (GGT 2018), 3-5 September 2018, Kuala Lumpur, Malaysia

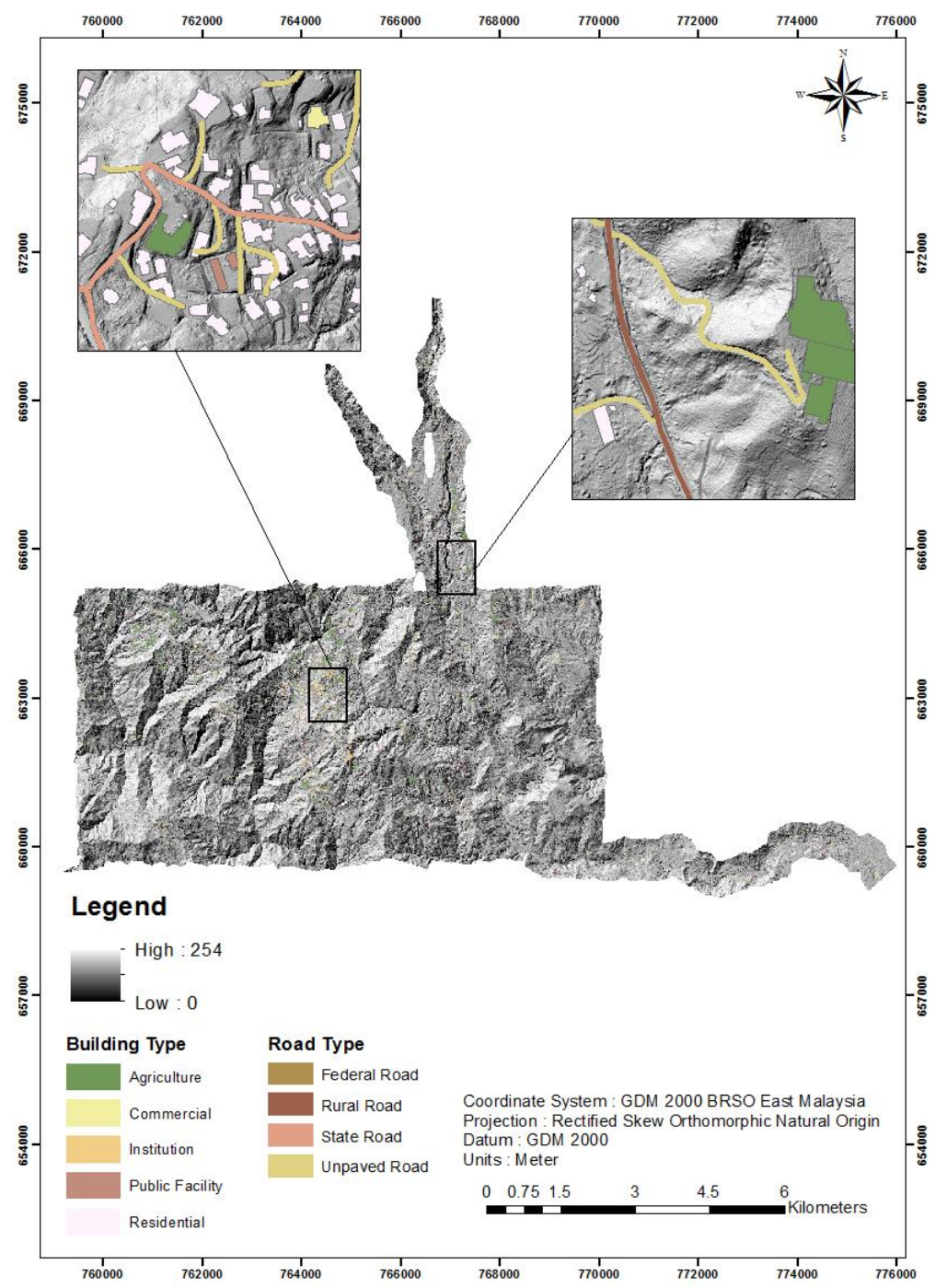

Figure 4: Landslide element at risk map of Kundasang

For Kundasang, (Tables 1), most of building and road features can be considered as element at risk. This can be seen by the high percentage of building classified as element at risk $(64.93 \%)$. The same comment made for the roads in Kundasang where $198.43 \mathrm{~km}$ out of 258.86 $\mathrm{km}$ total length of roads are at risk $(76.66 \%)$.

\begin{tabular}{|c|l|c|c|}
\hline Infrastructure & Attribute & Kundasang & $\begin{array}{c}\text { Kota } \\
\text { Kinabalu }\end{array}$ \\
\hline \multirow{2}{*}{ Building } & Total & 5805 & 28823 \\
\cline { 2 - 4 } & $\begin{array}{l}\text { Buildings } \\
\text { Within 100m } \\
\text { from } \\
\text { Landslide and } \\
\text { Man-Made } \\
\text { Slope Failure }\end{array}$ & 3769 & 6146 \\
\cline { 2 - 4 } & $\begin{array}{l}\text { Percentage } \\
(\%)\end{array}$ & 64.93 & 21.32 \\
\hline Road & Total (km) & 258.86 & 650.49 \\
\hline
\end{tabular}

\begin{tabular}{|l|l|c|c|}
\hline & $\begin{array}{l}\text { Roads Within } \\
100 \mathrm{~m} \text { from }\end{array}$ & & \\
& $\begin{array}{l}\text { Landslide and } \\
\text { Man-Made }\end{array}$ & 198.43 & 345.71 \\
\hline & $\begin{array}{l}\text { Slope Failure } \\
\text { (km) }\end{array}$ & & \\
\cline { 2 - 4 } & $\begin{array}{l}\text { Percentage } \\
(\%)\end{array}$ & 76.66 & 53.15 \\
\hline
\end{tabular}

Table 1: Statistics of selected roads within 100 meters distance in Kundasang

By using information and analysis from element-at-risk and hazard maps, the calculation of exposure map is possible. The method was completed in GIS environment by overlaying both information. The results of the exposure calculation can be illustrated as landslide exposure maps for Kota Kinabalu and Kundasang areas (Figures 5-6).

The exposure level of hazard for building and roads can be summarized in Tables 5 to 8 . For building in Kota Kinabalu (Table 5), about half on the buildings in the area were categorized as 'Medium' level $(50.52 \%)$, which was considered as the highest percentage. This was followed 
The International Archives of the Photogrammetry, Remote Sensing and Spatial Information Sciences, Volume XLII-4/W9, 2018 International Conference on Geomatics and Geospatial Technology (GGT 2018), 3-5 September 2018, Kuala Lumpur, Malaysia

by $21.62 \%$ for 'Very Low', $14.61 \%$ for 'High' and $12.95 \%$ for 'Low'. Building with 'Very High' level of exposure was showing a small percentage $(0.29 \%$ or 18 buildings) and was the lowest among all

For road in Kota Kinabalu (Table 6), there were only two levels of exposure which is 'Medium' and 'High'. From this, about $85 \%(292.76 \mathrm{~km})$ of the total roads were categorized as 'Medium' and the rests ( $15 \%$ or $52.95 \mathrm{~km})$ were considered as 'High'.

For building in Kundasang (Table 7), the highest class was the 'High' exposure level with $43.39 \%$ or about 1635 buildings. The second largest was 'Very High' level (26.78\%), followed by 'Medium' with 19.64\%, 'Low' with $9.71 \%$. Buildings with 'Very Low' were the lowest with $0.48 \%$ (about 18 buildings).

In the meantime, for road in Kundasang (Table 8), about $82 \%$ or $161.7 \mathrm{~km}$ of the road lengths were considered as 'High'. The rests $(18 \%$ or $36.73 \mathrm{~km})$ appeared as 'Low'.

\begin{tabular}{|l|l|l|l|}
\hline \multicolumn{4}{|l|}{ Kota Kinabalu (Building) } \\
\hline No & Level of Exposure & Total Buildings & $(\%)$ \\
\hline 1 & Very Low & 1329 & 21.62 \\
\hline 2 & Low & 796 & 12.95 \\
\hline 3 & Medium & 3105 & 50.52 \\
\hline 4 & High & 898 & 14.61 \\
\hline 5 & Very High & 18 & 0.29 \\
\hline
\end{tabular}

Table 1: Level of building exposure toward hazard in Kota Kinabalu

\begin{tabular}{|l|l|l|l|}
\hline \multicolumn{4}{|l}{ Kota Kinabalu (Road) } \\
\hline No & Level of Exposure & $\begin{array}{l}\text { Length of Road } \\
(\mathrm{km})\end{array}$ & $(\%)$ \\
\hline 1 & Medium & 292.76 & 84.68 \\
\hline 2 & High & 52.95 & 15.32 \\
\hline
\end{tabular}

Table 2: Level of road exposure toward hazard in Kota Kinabalu

\begin{tabular}{|l|l|l|l|}
\hline \multicolumn{4}{|l|}{ Kundasang (Building) } \\
\hline No & Level of Exposure & Total Buildings & $(\%)$ \\
\hline 1 & Very Low & 18 & 0.48 \\
\hline 2 & Low & 366 & 9.71 \\
\hline 3 & Medium & 740 & 19.64 \\
\hline 4 & High & 1635 & 43.39 \\
\hline 5 & Very High & 1009 & 26.78 \\
\hline
\end{tabular}

Table 3: Level of building exposure toward hazard in Kundasang

\begin{tabular}{|l|l|l|l|}
\hline \multicolumn{4}{|l|}{ Kundasang (Road) } \\
\hline No & Level of Exposure & Length of Road $(\mathrm{km})$ & $(\%)$ \\
\hline 1 & Low & 36.73 & 18.51 \\
\hline 2 & High & 161.7 & 81.49 \\
\hline
\end{tabular}

Table 4: Level of road exposure toward hazard in Kundasang

In general, majority of buildings and roads in Kota Kinabalu can be categorized as having 'Medium' level of exposure in terms of hazard while more than half of the buildings and roads in Kundasang area are located at the level of 'High' exposure and above. 
The International Archives of the Photogrammetry, Remote Sensing and Spatial Information Sciences, Volume XLII-4/W9, 2018 International Conference on Geomatics and Geospatial Technology (GGT 2018), 3-5 September 2018, Kuala Lumpur, Malaysia

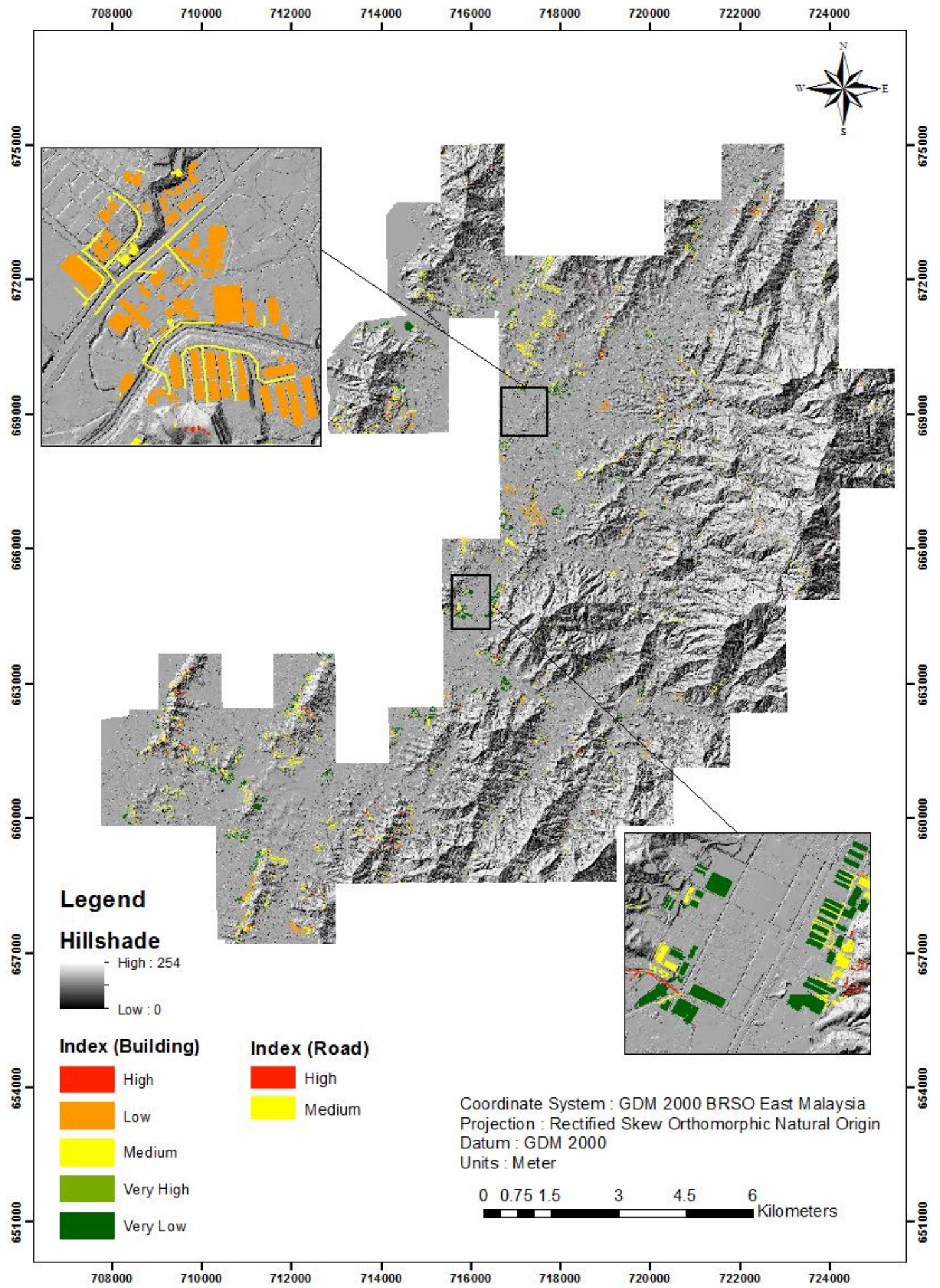

Figure 5:Landslide exposure map of Kota Kinabalu 
The International Archives of the Photogrammetry, Remote Sensing and Spatial Information Sciences, Volume XLII-4/W9, 2018 International Conference on Geomatics and Geospatial Technology (GGT 2018), 3-5 September 2018, Kuala Lumpur, Malaysia

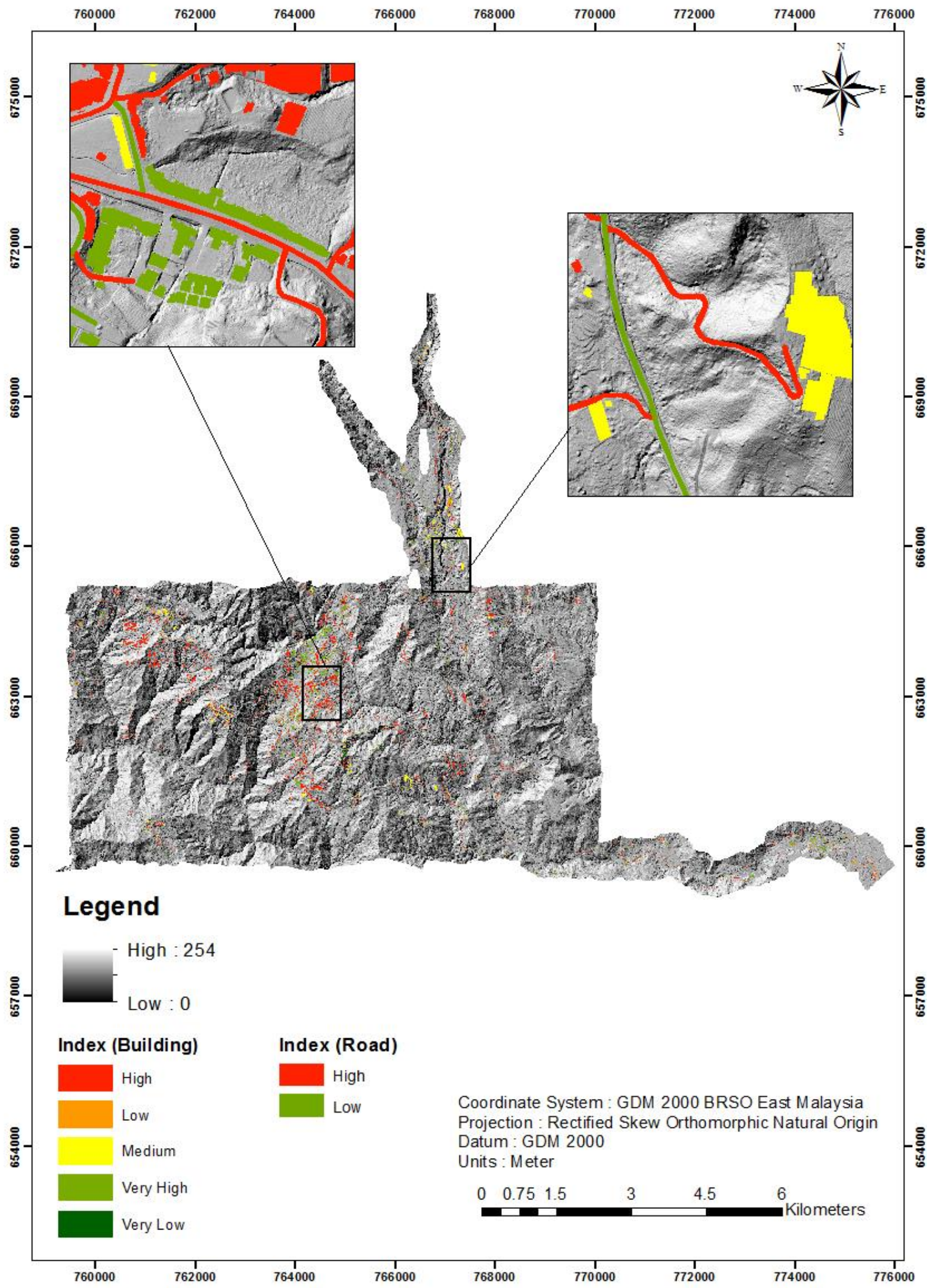

Figure 6:Landslide exposure map of Kundasang 
One of the critical parts in preparing element at risks information is the process of selecting features from the LiDAR data. For example, extracting roads, building, vegetation areas and other features which involving manual method. Features such as buildings, are extracted automatically from the LiDAR point cloud (i.e. building footprint) but others such are different vegetation areas required manual approach or semi-automatic classification process. Manual method or using image classification process will produce results to a certain accuracy level. Consequently, the maps need to be validated with existing features available such as from the Google Image or Google Street View. This is a time-consuming process considering the areas are large with many features which need to be identified. Therefore, the authors suggested in future, an automatic process to extract all features involved in element at risk should be considered to minimize processing time and reducing errors as compared to a manual approach. Object image analysis is one of the tools to be tested in the future to automatically extract these features. Another issue that can be highlighted is the LiDAR point clouds filtering technique. For example, some of the building footprints are misclassified as forested area. These point clouds should be classified with a better technique to reduce the misclassification error. This include the use of advanced filtering and classification techniques.

One of the important aspects in airborne LiDAR processing is a process to separate between ground and non-ground laser points. Problems in the filtering process will lead to a problem in landuse and landcover mapping. For example, buildings might be wrongly classified as ground terrain. This will affect the quality of element at risk mapping. In this case, airborne LiDAR filtering process should be done carefully that accounts for local condition of a specific area. This also requires careful assignment of values for important variables in the filtering algorithm. The results of this filtering process should be supported by strong quality checking (QC) procedures.

The result of exposure map is highly depending on the hazard map produced. The map shows the degree of element at risks located on the hazardous locations and how the building and road features are selected to be element at risks. The degree of accuracy in hazard map and element at risks reflects directly on how good the accuracy of exposure map. Therefore, the results of landslide exposure (or also can be described as hazardous footprints) can be improved in terms of its accuracy if the hazard map have a high success rate and reflects the data from the field visit. In other word, the accuracy of hazard map will affect the landslide exposure map produced and it is important to formulate hazard map at the highest accuracy.

\section{CONCLUSION}

This study has successfully presented a method to remotely extract the information from LiDAR data to assist with the landslide hazard and risk analysis. The method has been demonstrated to be suitable for landslide areas in Kota Kinabalu and Kundasang areas. However, investigation is needed to test whether the method could be applied for other landslides areas as the setting and physical condition are different.

\section{REFERENCES}

Brideau, M.-A. \& Roberts, N. J. 2015. Chapter 3 - Mass Movement in Bedrock A2 - Shroder, John F. In: Davies, T. (ed.) Landslide Hazards, Risks and Disasters. Boston: Academic Press.

Couture, R. \& Evans, S. G. 2006. Slow-moving Disintegrating rockslides on Mountain Slopes. Landslides, 49, 377-393.

De Bono, A. \& Mora, M. G. 2014. A global exposure model for disaster risk assessment. International Journal of Disaster Risk Reduction, 10, 442-451.

Du, S., Zhang, Y., Zou, Z., Xu, S., He, X. \& Chen, S. 2017. Automatic building extraction from LiDAR data fusion of point and grid-based features. ISPRS Journal of Photogrammetry and Remote Sensing, 130, 294-307.

Kumar, P., McElhinney, C. P., Lewis, P. \& McCarthy, T. 2013. An automated algorithm for extracting road edges from terrestrial mobile LiDAR data. ISPRS Journal of Photogrammetry and Remote Sensing, 85, 44-55.

McColl, S. T. 2015. Chapter 2 - Landslide Causes and Triggers A2 - Shroder, John F. In: Davies, T. (ed.) Landslide Hazards, Risks and Disasters. Boston: Academic Press.

McKean, J. \& Roering, J. 2004. Objective landslide detection and surface morphology mapping using highresolution airborne laser altimetry. Geomorphology, 57, 331-351.

Omar, S., Mohamed, Z. \& Razak, K. A. Landslide Mapping Using LiDAR in the Kundasang Area: A Review. 2016 Singapore. Springer Singapore, 355-367.

Razak, K. A., Straatsma, M. W., van Westen, C. J., Malet, J. P. \& de Jong, S. M. 2011. Airborne laser scanning of forested landslides characterization: Terrain model quality and visualization. Geomorphology, 126, 186-200.

Sharir, K., Simon, N. \& Roslee, R. 2016. Regional assessment on the influence of land use related factor on landslide occurrences in Kundasang, Sabah. AIP Conference Proceedings, 1784, 060015.

van Westen, C. J., Castellanos, E. \& Kuriakose, S. L. 2008. Spatial data for landslide susceptibility, hazard, and vulnerability assessment: An overview. Engineering Geology, 102, 112-131.

Revised August 2018 